\title{
Parallax correction in collocating CloudSat and Moderate Resolution Imaging Spectroradiometer (MODIS) observations: Method and application to convection study
}

\author{
Chunpeng Wang, ${ }^{1}$ Zhengzhao Johnny Luo, ${ }^{2}$ and Xianglei Huang ${ }^{1}$ \\ Received 12 April 2011; revised 1 June 2011; accepted 7 June 2011; published 8 September 2011. \\ [1] Parallax is associated with an apparent shift of the position of an object when viewed \\ from different angles. For satellite observations, especially observations with clouds, \\ it affects collocation of measurements from different platforms. In this study, we \\ investigate how the parallax problem affects the collocation of CloudSat and Moderate \\ Resolution Imaging Spectroradiometer (MODIS) observations of tropical convective \\ clouds by examining the impact of parallax correction on statistics of convective cloud \\ properties such as cloud top temperature (CTT) and buoyancy. Previous studies \\ circumvented the parallax problem by imposing a "flat-top" condition on the selection of \\ convective clouds, but it inadvertently biases the statistics toward convections at mature or \\ dissipating stages when convective plumes cease to grow but flatten out to form cirrus \\ anvils. The main findings of this study are the following: (1) Parallax correction \\ reduces CTT of convective clouds; the magnitude of the reduction increases with cloud \\ top height (CTH). (2) Parallax correction also reduces the spread of CTT estimates, \\ making it more closely clustered around the corresponding CTH. (3) The fraction of \\ convection with positive buoyancy decreases after the parallax correction. All these \\ changes that are due to parallax correction are most pronounced for convections above \\ 10-12 km, highlighting the importance of parallax correction in satellite-based study of \\ deep convection. With parallax correction applied, we further examine the contrast in \\ convective cloud buoyancy between land and ocean and day and night and the dependence \\ on convective cloud size; results are consistent with our general understanding of \\ tropical convection.
}

Citation: Wang, C., Z. J. Luo, and X. Huang (2011), Parallax correction in collocating CloudSat and Moderate Resolution Imaging Spectroradiometer (MODIS) observations: Method and application to convection study, J. Geophys. Res., 116, D17201, doi:10.1029/2011JD016097.

\section{Introduction}

[2] With the accumulation of A-Train satellite data [Stephens et al., 2002] that observe various components of the climate system in a nearly simultaneous way, more and more studies have been conducted to exploit the synergistic value among these different measurements. Clouds are one of the primary interests for A-Train satellite measurements. A number of instruments have been deployed on the A-Train constellation for this purpose including two active sensors (CloudSat and CALIPSO) and a suite of passive sensors (e.g., Moderate Resolution Imaging Spectroradiometer (MODIS), Atmospheric Infrared Sounder (AIRS), Tropospheric Emission Spectrometer (TES), and Microwave Limb Sounder (MLS)).

\footnotetext{
${ }^{1}$ Department of Atmospheric, Oceanic and Space Sciences, University of Michigan, Ann Arbor, Michigan, USA.

${ }^{2}$ Department of Earth and Atmospheric Sciences and NOAA CREST Center, City College of New York, New York, New York, USA.

Copyright 2011 by the American Geophysical Union. 0148-0227/11/2011JD016097
}

Several recent studies have exploited such synergy to gain new insights into cloud structure, climatology and the underlying physical/chemical processes [e.g., Kahn et al., 2008; Luo et al., 2008, 2009, 2010; Kato et al., 2010; Hong et al., 2010]. In a series of studies, Luo et al. [2008, 2009, 2010] utilized CloudSat radar reflectivity, MODIS $11 \mu \mathrm{m}$ brightness temperature (hereafter $11 \mu \mathrm{m} \mathrm{T} \mathrm{T}_{\mathrm{B}}$ ), and ambient temperature from European Centre for Medium-Range Weather Forecasts (ECMWF) operational analysis to estimate the buoyancy of convective clouds, identify life stages in their whole life cycles, as well as to estimate the entrainment rates. Kahn et al. [2008] analyzed CloudSat and CALIPSO data to evaluate the accuracy of AIRS cloud retrievals for a wide range of cloud types and to quantify the biases and variability of cloud top height retrieved by AIRS operational algorithm as a function of cloud types.

[3] An important question facing multisatellite synergy is collocation. A-Train constellation is designed to simplify the collocation problem by flying satellites in formation. A common approach for collocation is to ensure that the ground footprints of the two sensors match each other (this 


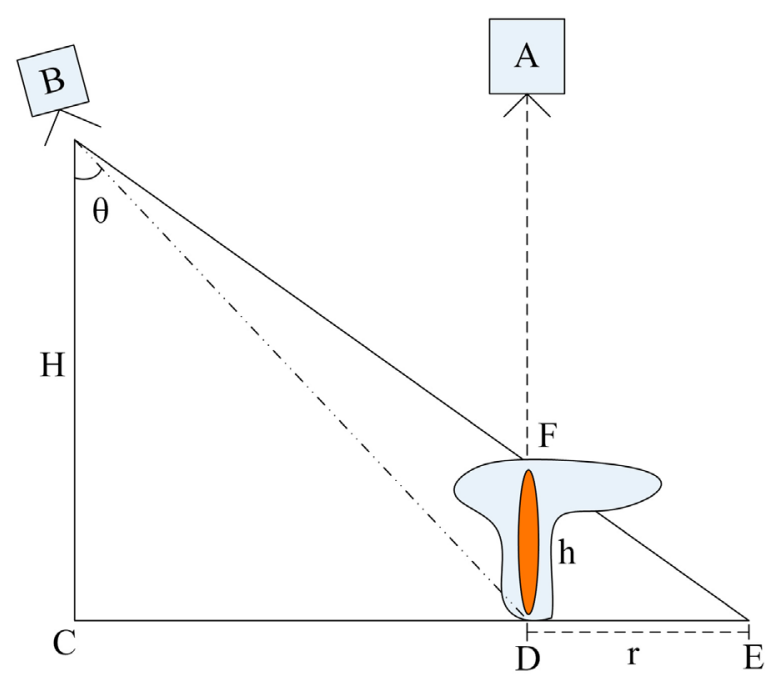

Figure 1. A schematic showing the viewing geometries of two satellites to illustrate the parallax problem. Note this drawing is for illustration only, so horizontal and vertical dimensions are not to scale.

method has been used in producing the MODIS-AUX product, which matches each CloudSat profile with $3 \times$ 5 grids of $1 \mathrm{~km}$ MODIS data centered on the CloudSat profile location). This approach works well for objects near the surface, regardless of viewing angles; however, for an object that is above the ground or hangs in the air (such as cloud), the parallax problem would arise resulting in mismatch. Figure 1 uses a sketch to illustrate this problem: instrument $\mathrm{A}$ observes the cloud in a nadir view with the ground footprint at point $\mathrm{D}$, while instrument $\mathrm{B}$ observes the same cloud top (point F) from a slantwise path with ground footprint at point E. If we simply collocate the ground footprint, we would then use a different measurement from instrument B (the dash-dotted line in Figure 1) for which the viewing path does not intersect the cloud at all. Therefore, to ensure exact collocation in cloud observations, a shift in ground footprints for instrument $B$ is required (in this case, it would be from point $\mathrm{D}$ to point $\mathrm{E}$ ). This shift is called parallax correction. It is related to a number of factors including satellite viewing angle, satellite altitude and cloud height. The parallax problem can also be exploited to retrieve useful information about clouds. For example, the stereoscopic technique that is often used to retrieve cloud top height [e.g., Hasler, 1981; Diner et al., 1998] is based on the same parallax principle as illustrated in Figure 1.

[4] The effect of parallax correction is small if the cloud object occupies a large enough area and is relatively homogeneous over the range comparable to the parallax correction (e.g., stratiform clouds). However, it would become important when either the cloud object is small or the cloud properties are nonuniform over a short distance, or when both of them hold true. Such situations are often encountered in the studies of convective clouds. Consider now an example of using CloudSat and MODIS (aboard Aqua) to study convective clouds. CloudSat observes clouds in a nadir view while MODIS operates in cross-track scanning mode with zenith angle from $-65^{\circ}$ to $65^{\circ}$. Because both are part of the A-Train constellation, both satellites fly at an altitude $\sim 700 \mathrm{~km}$. The ground trajectories of the two satellites, however, are $\sim 230 \mathrm{~km}$ apart in the tropics and cross over each other in the polar region. This situation is illustrated in Figure 1, with satellite A as CloudSat and satellite B as MODIS. In generating MODIS-AUX (a standard CloudSat data product), the collocation is done by matching the positions of CloudSat surface footprints with those of MODIS. As pointed out in the previous paragraph, such collocation strategy could introduce a parallax bias. To further illustrate this problem, Figure 2 shows a segment of CloudSat radar reflectivity (Figure 2, top) and its ground track (yellow line in Figure 2, bottom) overlapped with MODIS $11 \mu \mathrm{m} \mathrm{T}_{\mathrm{B}}$. For the convective plume between $126.70^{\circ} \mathrm{E}, 3.70^{\circ} \mathrm{N}$ and $126.75^{\circ} \mathrm{E}, 3.89^{\circ} \mathrm{N}$, if parallax error is not corrected, the "collocated" MODIS $11 \mu \mathrm{m}$ TB is $272.3 \mathrm{~K}$, which poses a stark contrast with the cloud top height (CTH) at $15.18 \mathrm{~km}$ as measured by CloudSat cloud profiling radar. According to ECMWF interim reanalysis [Simmons et al., 2006; Uppala et al., 2008], the ambient temperature at $15.18 \mathrm{~km}$ at this location was only $201.67 \mathrm{~K}$. One can clearly see in Figure 2 that the parallax displacement, although very small $(\sim 5 \mathrm{~km})$, shifts the matched points from the center of the convective plume to the edge. Convective edge usually consists of thin cirrus anvil which allows a significant amount of the warm radiation from below the cloud deck to leak through resulting in a much higher $11 \mu \mathrm{m} \mathrm{T}_{\mathrm{B}}$. When parallax correction is applied to this plume (red dots in Figure 2, bottom), the corresponding MODIS $11 \mu \mathrm{m} \mathrm{T}_{\mathrm{B}}$ for this tall convective tower becomes 206.3 K, significantly lower than the one without parallax correction and is in line with the ambient temperature at this height.

[5] This parallax problem has been realized in previous studies by Luo et al. [2009, 2010]. Their tentative solution was to remove the smaller convective plumes by imposing a condition that the standard deviation of the $11 \mu \mathrm{m}$ brightness temperatures over neighboring MODIS pixels be less than $3 \mathrm{~K}$ for CTH within 3-9 km and less than $1 \mathrm{~K}$ for $\mathrm{CTH}$ above $12 \mathrm{~km}$. Such a stringent condition effectively filtered out scenes with nonuniform cloud tops and retained only those with relatively flat cloud tops (which we call "flattop" condition hereafter), making parallax correction less of an issue. However, the selected samples under this condition will favor convective clouds at the mature and dissipative stages when plumes cease to grow but flatten out to form anvils, and will tend to exclude those in the incipient stage whose cloud tops are still "irregular." Since convective clouds in the incipient stage tend to have positive buoyancy near the cloud top, such a constraint can inadvertently affect the statistics related to convective top buoyancy, such as those shown by Luo et al. [2009, 2010].

[6] The objective of this study is to apply the parallax correction to convection observed by CloudSat and MODIS data and remove the aforementioned flat-top constraint. Moreover, we evaluate the impact of parallax correction on statistics collected about convective clouds and compare the results with those of Luo et al. [2009, 2010]. The rest of the paper is organized as follows: section 2 describes the data sets and algorithm for parallax correction; some 


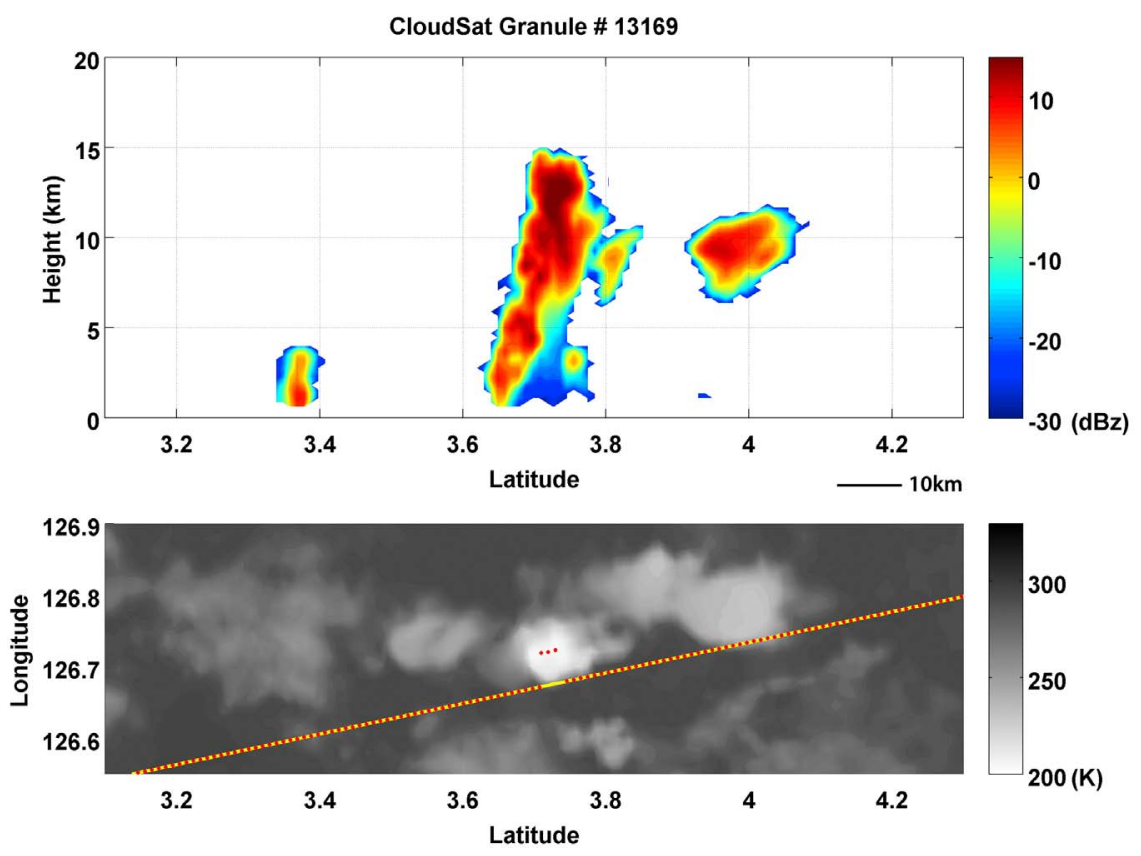

Figure 2. (top) CloudSat radar reflectivity (in dBz) observed at 17:21 UTC on 18 October 2008. (bottom) Concurrent measurements of MODIS $11 \mu \mathrm{m}$ brightness temperature $\left(\mathrm{T}_{\mathrm{B}}\right.$, in $\left.\mathrm{K}\right)$. The yellow line is CloudSat ground track without parallax correction. The red dotted line segment represents the parallax correction.

case studies are also presented. Statistical results and comparisons with analysis without parallax correction are presented in section 3. Discussion and conclusion are given in section 4 .

\section{Data Description and Methodology}

\subsection{CloudSat and MODIS Data}

[7] Data used in this study are mostly from the CloudSat mission and MODIS aboard Aqua. Launched in 2006 as part of the A-Train constellation, CloudSat is a Sun-synchronous polar-orbiting satellite flying at the altitude of $705 \mathrm{~km}$ [Stephens et al., 2002]; it carries a $94 \mathrm{GHz}$ nadir-viewing cloud profiling radar (CPR) with a vertical resolution of $480 \mathrm{~m}$ oversampled to $240 \mathrm{~m}$ and ground footprint of approximately $1.7 \mathrm{~km}$ along track and $1.3 \mathrm{~km}$ cross track. We mainly use CloudSat 2B-GEOPROF data containing cloud mask and radar reflectivity. Specifics of the CloudSat mission and data products are given by Stephens et al. [2008] and the CloudSat Data Processing Center (http://www.cloudsat.cira.colostate. edu). MODIS aboard Aqua satellite was launched in 2002 and measures narrowband radiances in 36 spectral bands from 0.415 to $14.24 \mu \mathrm{m}$ with wavelength-dependent nadir spatial resolutions from $250 \mathrm{~m}$ to $1 \mathrm{~km}$ [Barnes et al., 1998; Parkinson, 2003; Platnick et al., 2003].

\subsection{Selection of Convective Clouds}

[8] We analyze all data collected within the tropics $\left(30^{\circ} \mathrm{S}-\right.$ $30^{\circ} \mathrm{N}$ ) in the entire year of 2008 . Following Luo et al. [2009], CloudSat reflectivity profiles are used to obtain CTH while MODIS imageries of $11 \mu \mathrm{m} \mathrm{T}_{\mathrm{B}}$ are used to estimated cloud top temperature (CTT). Shallow convection is not the center of our interest. Moreover, the parallax correction for shallow convective cloud can be smaller than
$1 \mathrm{~km}$ (refer to section 2.3 for a discussion on this), i.e., within the same MODIS $1 \mathrm{~km}$ pixel. Meanwhile, convections penetrating the tropical tropopause are rare and we are only interested in overall statistics. Therefore, we limit our analysis to $\mathrm{CTH}$ between 6 and $18 \mathrm{~km}$. The corresponding geolocation coordinates, solar zenith angle and sensor viewing geometry of each MODIS $1 \mathrm{~km}$ pixel are extracted from the MODIS/Aqua $1 \mathrm{~km}, 5$ min wide swath along CloudSat, normally known as MAC03S1.002 product. The ambient temperature is obtained from temporal interpolation of 6-hourly ECMWF interim reanalysis temperature fields. ECMWF interim is the latest reanalysis product by ECMWF [Simmons et al., 2006; Uppala et al., 2008] with a horizontal resolution of $1.5^{\circ} \times 1.5^{\circ}$.

[9] For cloud decks, $11 \mu \mathrm{m} \mathrm{T}_{\mathrm{B}}$ represents approximately the temperature at an emission level where cloud IR optical thickness $\left(\Delta \tau_{\text {cld }}=1\right)$ is about 1 . So $11 \mu \mathrm{m} \mathrm{T}_{\mathrm{B}}$ is always warmer than the CTT (except for some cases of overshooting to the stratosphere). Luo et al. [2010] utilized collocated CALIPSO lidar and CloudSat radar data to estimate the correction for $11 \mu \mathrm{m} \mathrm{T}_{\mathrm{B}}$ case by case. Here, we adopt a simplified approach by using a lookup table to link CloudSat reflectivity profile characteristics to the correction. The idea is that a "packed" cloud top (which will show up as a larger vertical gradient in radar reflectivities) needs a smaller correction because the emission level is close to the physical cloud top whereas a fuzzy cloud top needs a larger correction. Once CTT is determined, convective buoyancy is derived from the difference between CTT and ambient temperature at the same altitude, as is done by Luo et al. [2010].

[10] Another modification to the work by Luo et al. [2010] is the way statistics are constructed. In the work of Luo et al. [2010], each selected CloudSat convective profile 


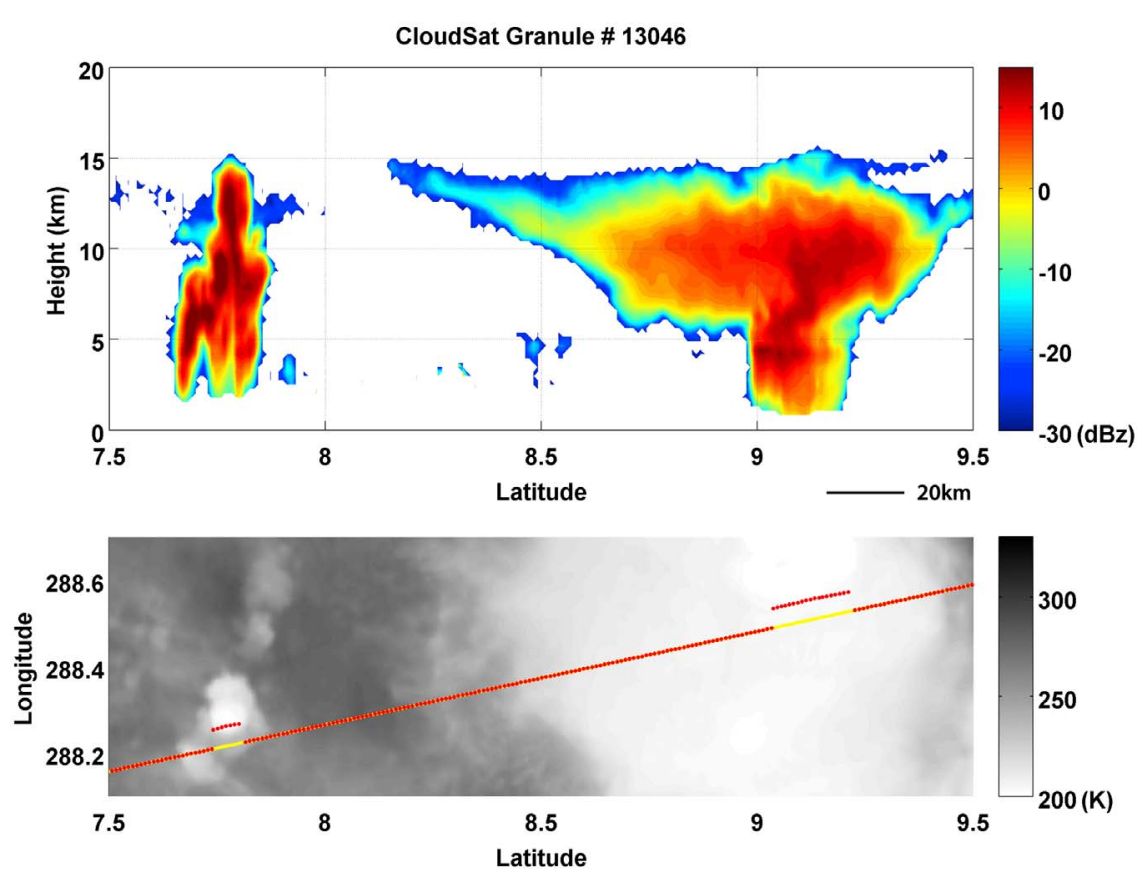

Figure 3. The same as Figure 2 except for the observations made at 06:37 UTC on 10 October 2008.

is counted equally in calculating the histogram of buoyancy. But since larger convective clouds contain more radar profiles, the statistics may be biased in favor of larger systems. Here instead, we treat each convective cloud (defined as neighboring CloudSat profiles, satisfying the "convective core" condition as defined by Luo et al. [2010]) as one entity and use the highest $\mathrm{CTH}$ to define buoyancy for the whole plume. Sometimes a separate layer of cirrus can be seen on top of a convective plume. We exclude such cases since the upper cirrus layer affects the MODIS $11 \mu \mathrm{m} \mathrm{T}$ and makes it a difficult task to calculate the corresponding CTT for the convective tower.

\subsection{Parallax Correction}

\subsubsection{Geometric Consideration}

[11] Consider Figure 1 and assume instrument $\mathrm{A}$ is the CloudSat cloud profiling radar (CPR) and instrument $\mathrm{B}$ is MODIS aboard Aqua. In order to match the cloud observation in the field of view, the ground footprint of MODIS should be at point E. Given the similarity of triangular BCE and triangular FDE and the MODIS viewing zenith angle at point $\mathrm{D}$, i.e., $\mathrm{CBD}$ ), the length of the displacement vector from point $\mathrm{D}$ to point $\mathrm{E}, \vec{r}$, can be written as

$$
|\vec{r}|=\frac{h H \tan \theta}{H-h}
$$

where $H=705 \mathrm{~km}$ is the operational altitude of Aqua; $\theta$ denotes the viewing zenith angle of the MODIS measurement with ground footprint at point $\mathrm{D} ; h$ is the CTH derived from CloudSat. The direction of $\vec{r}$ is given by viewing azimuth angle $(\phi)$, defined as the angle between vector $\overrightarrow{D C}$ and local geodetic north [Nishihama et al., 1997]. In our following equation, $\pi$ is added to $\phi$ in order to obtain the angle between vector $\overrightarrow{C D}$ and local geodetic north. In the tropics, $\theta$ is $\sim 18^{\circ}$ for MODIS pixels around the CloudSat ground track. On the basis of (1), it can be inferred that $h$ needs to be at least $3 \mathrm{~km}$ in order to make displacement distance larger than $1 \mathrm{~km}$, the spatial resolution of MODIS IR pixel.

[12] Denote the latitude and longitude of point $\mathrm{D}$ as $Y_{D}$ and $X_{D}$ in radian, respectively. Then the latitude and longitude of point $\mathrm{E}$ can be written as

$$
\begin{aligned}
& Y_{E}=Y_{D}+|\vec{r}| \cos (\phi+\pi) / R_{E}, \\
& X_{E}=X_{D}+|\vec{r}| \sin (\phi+\pi) /\left(R_{E} \cos Y_{D}\right),
\end{aligned}
$$

where $R_{E}$ is the radius of the earth. Through (1) and (2), the parallax correction (i.e., DE) can be computed and MODIS $11 \mu \mathrm{m} \mathrm{T}_{\mathrm{B}}$ for point $\mathrm{E}$ is recorded and used in our analysis. 2.3.2. Case Studies

[13] We present two cases to further illustrate the parallax problem. The first case has been briefly discussed in section 1 (Figure 2). The convective cloud is located near $3.7^{\circ} \mathrm{N}$, $126.7^{\circ} \mathrm{E}$ : red dots represent point $\mathrm{E}$ in Figure 1 (with parallax correction), and yellow dots correspond to point D (without parallax correction). The shift from the yellow dots to the red dots is about $5.1 \mathrm{~km}$, but it results in a change of $11 \mu \mathrm{m} \mathrm{T}_{\mathrm{B}}$ by $66 \mathrm{~K}$ (from 272 to $206 \mathrm{~K}$ ). Such a large temperature gradient is also reflected in a large standard deviation of $25 \mathrm{~K}$ for the $11 \mu \mathrm{m} \mathrm{T}_{\mathrm{B}}$ from the $3 \times 5$ grids of $1 \mathrm{~km}$ MODIS data centered on the CloudSat profile location. Clearly, parallax correction is critical for the correct estimation of CTT associated with this convective plume.

[14] Another example is shown in Figure 3. Two convective clouds are identified: one is an isolated deep convection $\left(\sim 7.8^{\circ} \mathrm{N}, 288.3^{\circ} \mathrm{E}\right)$ and the other is a much larger convective system $\left(\sim 9.1^{\circ} \mathrm{N}, 288.4^{\circ} \mathrm{E}\right)$. The former case is just like the one in Figure 2. A small parallax shift translates to a large dif- 


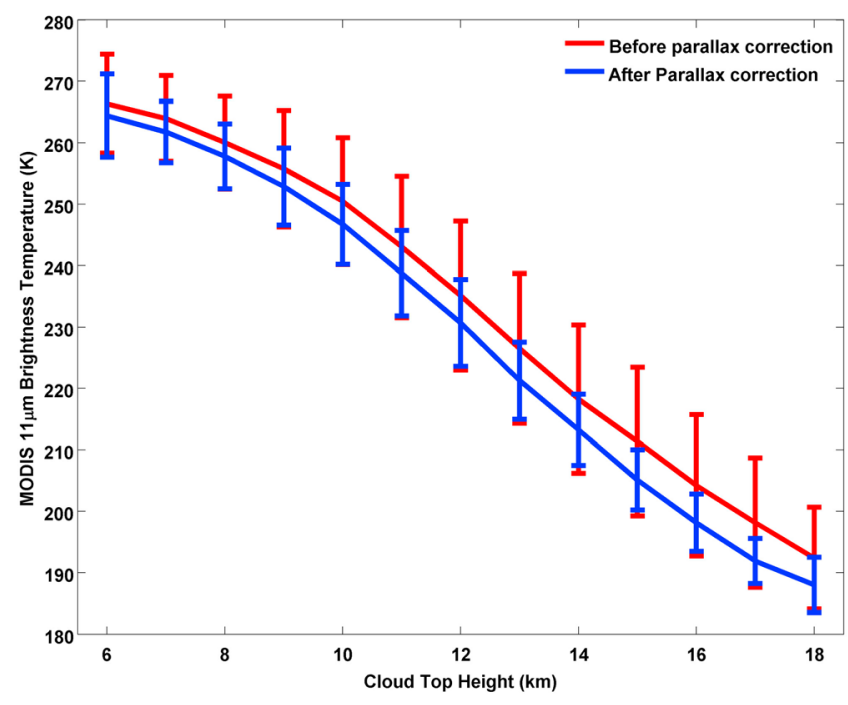

Figure 4. Mean and standard deviation of MODIS $11 \mu \mathrm{m}$ $\mathrm{T}_{\mathrm{B}}$ as a function of cloud top height $(\mathrm{CTH})$. A total of 16,218 cases over the year of 2008 are used to compute the statistics. The bin size of CTH is $1 \mathrm{~km}$. Red and blue lines show the results before and after the parallax correction, respectively.

ference in the $11 \mu \mathrm{m} \mathrm{T}_{\mathrm{B}}(\sim 30 \mathrm{~K})$. The latter case, in contrast, possesses some very different characteristics such as having a well-defined anvil extending over $100 \mathrm{~km}$, as shown in the vertical cross section by CloudSat. Most likely it is a convective system at its mature stage or perhaps even heading toward dissipation (once the plume rains out the precipitating particles). The anvil is rather flat and homogeneous, as the standard deviations of the $3 \times 511 \mu \mathrm{m} \mathrm{T}_{\mathrm{B}}$ measurements surrounding the convective cores are only about $0.28 \mathrm{~K}$. Parallax correction makes little difference to this case, as far as CTT is concerned. It should be noted that the former case, i.e., the small deep convective plume, would have been filtered out if the flat-top criteria of Luo et al. [2010] were used but the latter case will remain.

[15] These cases help illustrate the scenarios where parallax correction will make a difference (smaller systems) and where it will not (larger systems with a flat top). Section 3 focuses on statistical analysis (based on tens of thousands of cases) to examine the effects of parallax correction on estimation of CTT and convective buoyancy, as well as how these effects depend on cloud height, cloud size, etc.

\section{Results and Interpretations}

[16] Following the method described in section 2.2, 16,218 convective clouds are identified from CloudSat data over the tropics $\left(30^{\circ} \mathrm{S}-30^{\circ} \mathrm{N}\right)$ for the entire year of 2008 . Figure 4 shows the mean MODIS $11 \mu \mathrm{m} \mathrm{T}$, as well as the standard deviation, as a function of CTH. Two line are shown: one with parallax correction (blue) and the other without (red). The bin size for CTH is $1 \mathrm{~km}$. Several findings deserve discussion.

[17] 1. The mean $T_{B}$ values become smaller after the parallax correction (the blue line is consistently lower than the red line). This can be understood as follows: some of the
$T_{B}$ reading without parallax correction includes the contribution from both convective plume and atmospheric layers or surface below it, as demonstrated in Figure 2. It is most likely that the neighborhood of the convective plume consists of clouds with lower height and warmer $T_{B}$, or even clear-sky scenes, since convective plumes usually bulge out from the cloud deck (our selection of the highest-reaching CloudSat profile as the representative CTH for each convective cloud also contributes to this difference). Figure 4 also shows that the parallax-induced difference in $T_{B}$ increases with CTH. For example, the mean values differ by $2 \mathrm{~K}$ at $\mathrm{CTH}$ of $7 \mathrm{~km}$ and it increases to $7.2 \mathrm{~K}$ at $15 \mathrm{~km}$. This is because the surrounding of a taller convective plume is less likely to be colder and higher than the plume itself (e.g., it is more likely for a $7 \mathrm{~km}$ convective plume to be sandwiched by taller neighbors than a $15 \mathrm{~km}$ plume). Therefore, $\mathrm{T}_{\mathrm{B}}$ without parallax correction tends to come from a scene warmer than the convective plume (as illustrated in Figures 2 and 3).

[18] 2. The standard deviations of the $T_{B}$ after the parallax correction are consistently smaller than those before the correction. Such a reduced spread can be understood as reflecting an overall improved collocation of CTH (from CloudSat) and $\mathrm{T}_{\mathrm{B}}$ (from MODIS). In other words, the estimated $T_{B}$ is now more closely clustered around the "true" value for that height level (e.g., no more $272.3 \mathrm{~K}$ for $15.18 \mathrm{~km}$, as shown in Figure 2). The decrease in spread is more pronounced for higher convection than for lower convection. Together with (1), these changes suggest that parallax correction is particularly important for studying deep convection.

[19] After MODIS $11 \mu \mathrm{m} \mathrm{T}_{B}$ is converted to CTT, we calculate the difference between CTT and the ambient temperature $\left(\mathrm{T}_{\text {env }}\right): \Delta \mathrm{T} \equiv \mathrm{CTT}-\mathrm{T}_{\text {env }}$, which is used by Luo et al. [2010] as an indicator of convective buoyancy. Our focus is again placed on contrasting the statistics before and after parallax correction. Figure 5 shows the histograms of $\Delta \mathrm{T}$ as a function of CTH (2-D histograms). The histograms are normalized at each $\mathrm{CTH}$ interval so that the total occurrence adds up to $100 \%$ at each CTH level. Consistent with the $11 \mu \mathrm{m} \mathrm{T}_{\mathrm{B}}$ statistics in Figure 4, the histogram before parallax correction shows a larger spread than that after the correction, especially for CTH $>8 \mathrm{~km}$. Figure 5 also shows that for the cases with CTH above $12 \mathrm{~km}$, negative buoyancy is dominant. This is consistent with the fact that $12 \mathrm{~km}$ happens to correspond to the mean level of neutral buoyancy (LNB) for the tropics as estimated from the Air Force Laboratory reference tropical profile [Ellingson et al., 1991]; convection ascending beyond the LNB will likely have colder top than the environment, thus negative buoyancy.

[20] Figure 6 presents the fraction of convection cases with positive buoyancy as a function of CTH from 6 to $18 \mathrm{~km}$ (i.e., sampling from cumulus congestus to deep convection). Results from three different analysis methods are shown: (1) with parallax correction (black), (2) without parallax correction (red), and (3) without parallax correction but with the flat-top constraint imposed (blue), mimicking Luo et al. [2009, 2010]. Out of 16,218 convective clouds analyzed in this study, only $33.9 \%$ pass the flat-top condition. In general, flat-top convection (blue) has the smallest occurrence frequency of positive buoyancy. This is expected 

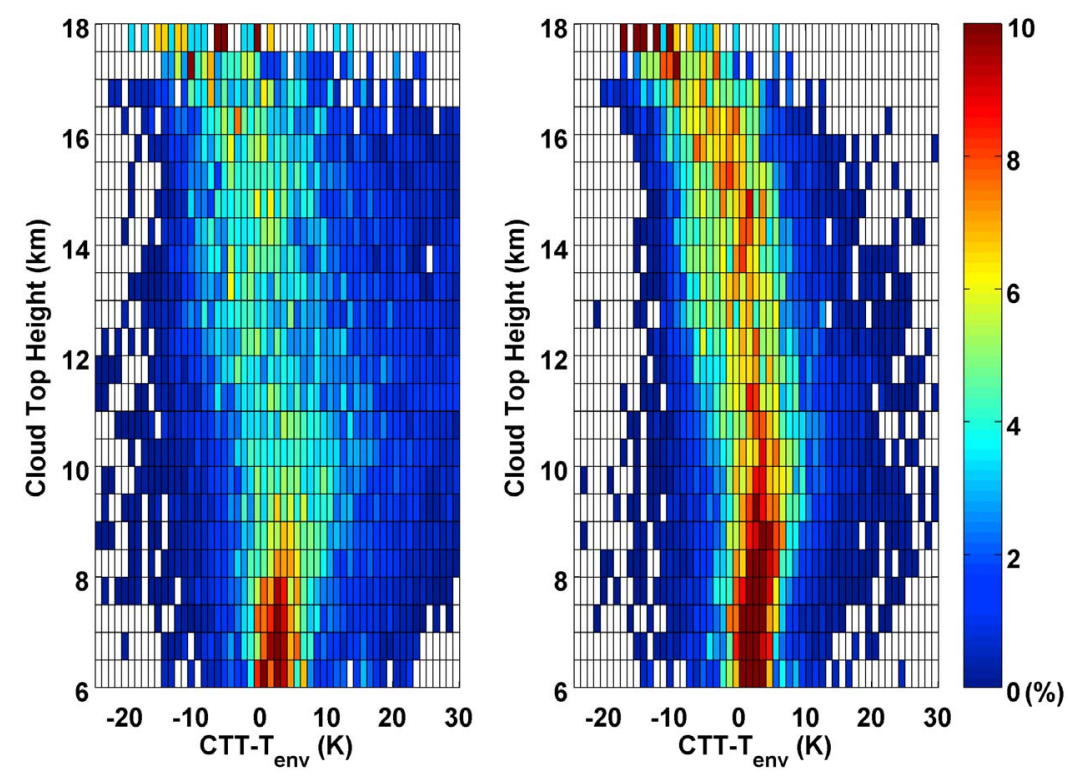

Figure 5. Histograms of $\Delta \mathrm{T} \equiv \mathrm{CTT}-\mathrm{T}_{\mathrm{env}}$ as a function of $\mathrm{CTH}$ (2-D histogram) for results from (left) before and (right) after parallax correction. The bin size of CTH is $0.5 \mathrm{~km}$ and that of CTT $-\mathrm{T}_{\text {env }}$ is $1 \mathrm{~K}$. The histograms are normalized at each CTH interval so that the total occurrence adds up to $100 \%$ at each CTH level.

since the constraint biases the selection of convective clouds toward those at mature and dissipating stages. Comparing results with parallax correction (black) with those without (red), the former shows a smaller fraction of positive buoyancy. This is in line with the finding from Figure 4; that is, parallax correction tends to reduce the $11 \mu \mathrm{m} \mathrm{T}_{\mathrm{B}}$, resulting in a lower CTT and hence lessening the chance of having positive buoyancy. Another consistent feature shown

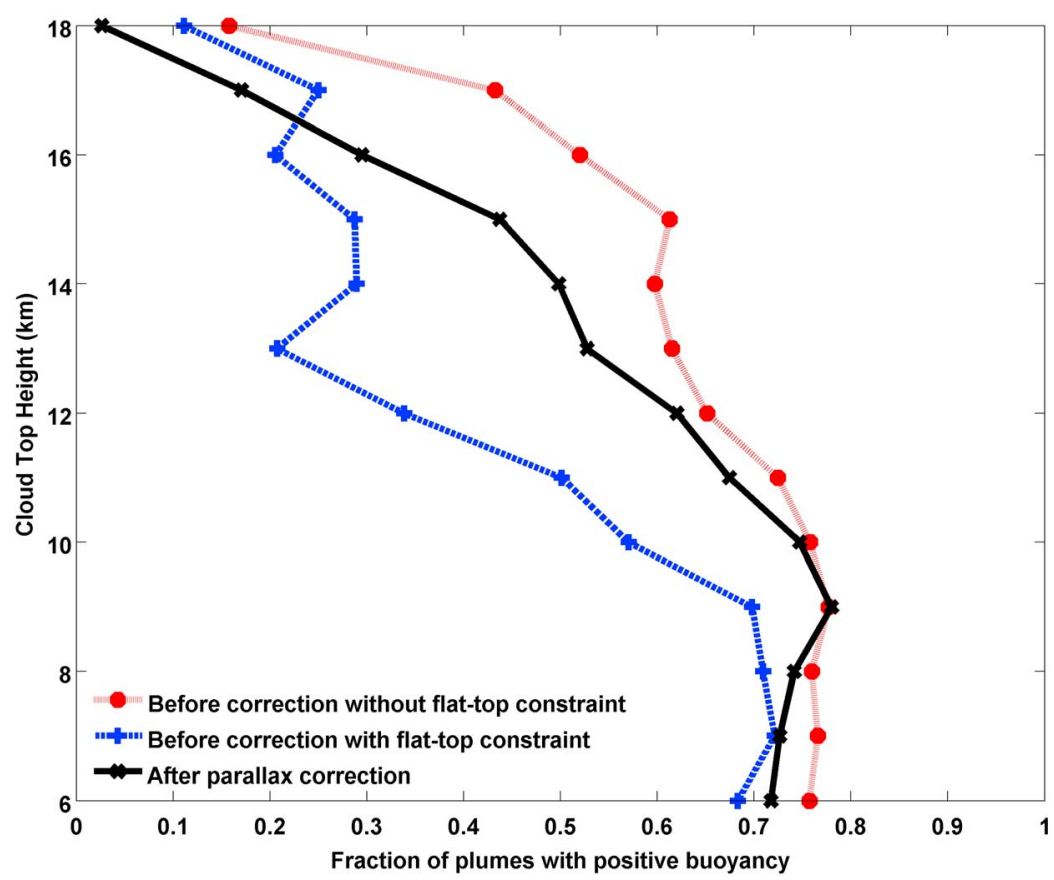

Figure 6. Fraction of convective clouds with positive buoyancy as a function of cloud top height. Results from three different analysis methods are shown: (1) with parallax correction (black line), (2) without parallax correction (red line), and (3) without parallax correction but with the flat-top constraint imposed (blue line), mimicking the work by Luo et al. [2009, 2010]. A total of 16,218 cases are used for computing these statistics. The bin size of cloud top height is $1 \mathrm{~km}$. 


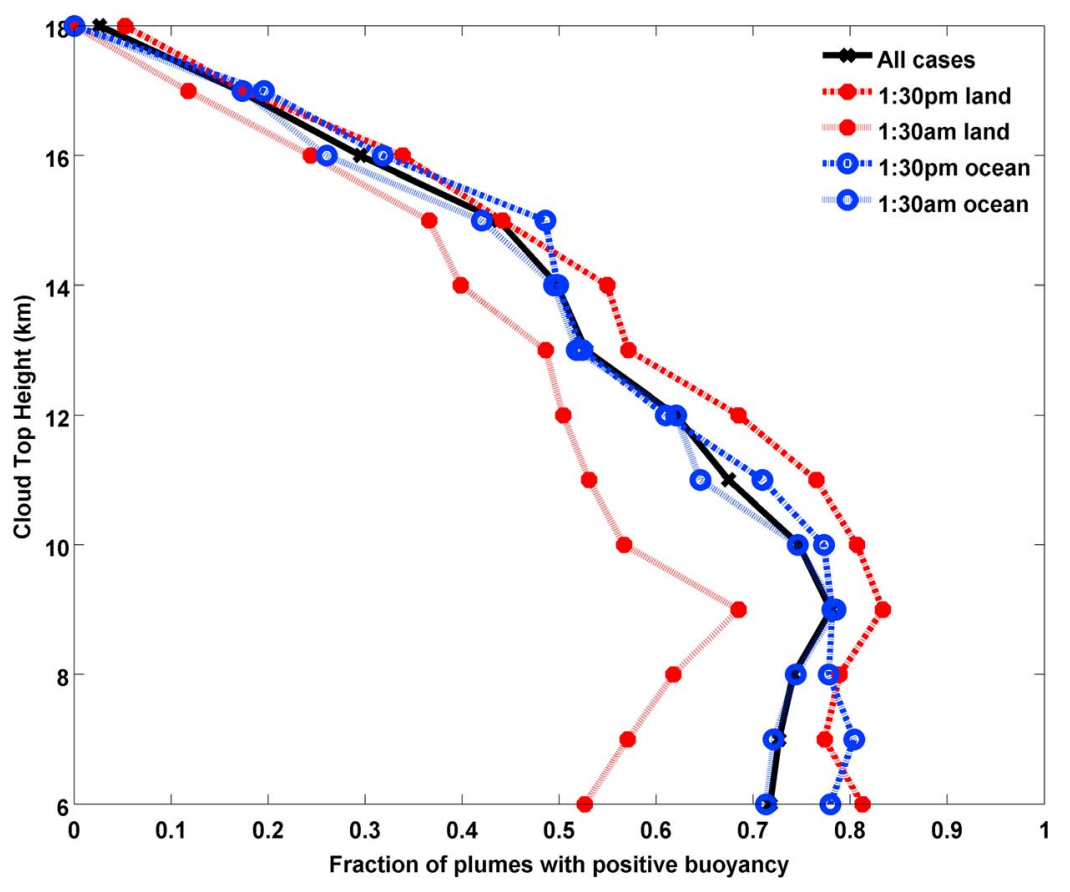

Figure 7. The same as Figure 6 except for four subgroups: daytime and nighttime over the land (red lines) and daytime and nighttime over the oceans (blue lines). Dark dashed lines are for 01:30 LT observations, and light-colored dashed lines are for 13:30 LT observations. Only the results from parallax correction without the flat-top constraint are shown here. The overall statistics (the same as the black line in Figure 6) are shown as the black line.

in Figure 6 is that parallax correction makes a larger difference for higher $\mathrm{CTH}$. This difference can be seen by comparing the red and black lines for 6-9 km versus for 9$16 \mathrm{~km}$. The former shows small differences, whereas the latter differs by $0.1-0.2$, especially above $12 \mathrm{~km}$. Once again, this highlights the importance of the correction for deep convection.

[21] The Sun-synchronous nature of A-Train satellites implies that measurements in the tropics are taken around 01:30 and 13:30 local time (LT). Although they are not enough to delineate the entire diurnal cycle, contrasting observations from the daytime (13:30 LT) and nighttime (01:30 LT) overpasses may still provide a means to at least partially reveal the diurnal differences. There are also landocean differences for tropical convection. Figure 7 shows the fraction of convective clouds with positive buoyancy as a function of CTH, just like Figure 6, but separated into four different subgroups: daytime over land, daytime over ocean, nighttime over land, and nighttime over ocean. Figure 7 suggests that over land, statistics from 01:30 LT measurements are quite different from that at 13:30 LT. The fraction of positive buoyancy cases over land is much larger at 13:30 LT than that at 01:30 LT. In contrast, the diurnal difference over the oceans is very small. This seems to be consistent with our understanding of diurnal cycle of tropical convection. The diurnal amplitude over the land is greater than that over the ocean and the peak time for continental convection is in the afternoon, closer to the 13:30 LT than 01:30 LT [Yang and Slingo, 2001; Tian et al., 2004; Liu et al., 2008].

[22] In addition to examining the statistics at different cloud top heights, it is also informative to composite the positive buoyancy statistics with respect to the horizontal size of the core of a convective cloud as observed by the CloudSat radar reflectivity. One cautious note is that the horizontal size deduced from CloudSat may be somewhat different from real size as inferred from geostationary imageries which are capable of capturing a plan view of the entire convective systems. Results are shown in Figure 8 in terms of the fraction of convective clouds with positive buoyancy sorted by the horizontal span of these clouds. Generally, the fraction of positive buoyancy cases decreases with the size of connective core (Figure 8). So does the mean temperature difference between the cloud top and ambient environment (not shown here), which drops from $2.8 \mathrm{~K}$ for the $0-5 \mathrm{~km}$ bin to $-3.4 \mathrm{~K}$ for the $35-40 \mathrm{~km}$ bin. These results suggest that smaller convective plumes are more likely to be actively growing (positive buoyancy). This is consistent with our understanding of the convective life cycle and with previous studies [see, e.g., Luo et al., 2008]. The positive buoyancy fraction levels off after $\sim 35 \mathrm{~km}$. As shown by the histogram in Figure 8, the number of cases with horizontal span $>35 \mathrm{~km}$ only consist of $1.39 \%$ of total observations. Moreover, such large convective core occupies a considerate portion of the $1.5^{\circ} \times 1.5^{\circ}$ grid box. Hence it might not be a good approximation any more to assume the ERA interim temperature of that grid box being the cloud-free ambient temperature. Therefore, such level off beyond $35 \mathrm{~km}$ may not be statistically robust.

\section{Conclusion}

[23] Parallax problem affects collocation of satellite measurements from different platforms. This problem is especially 


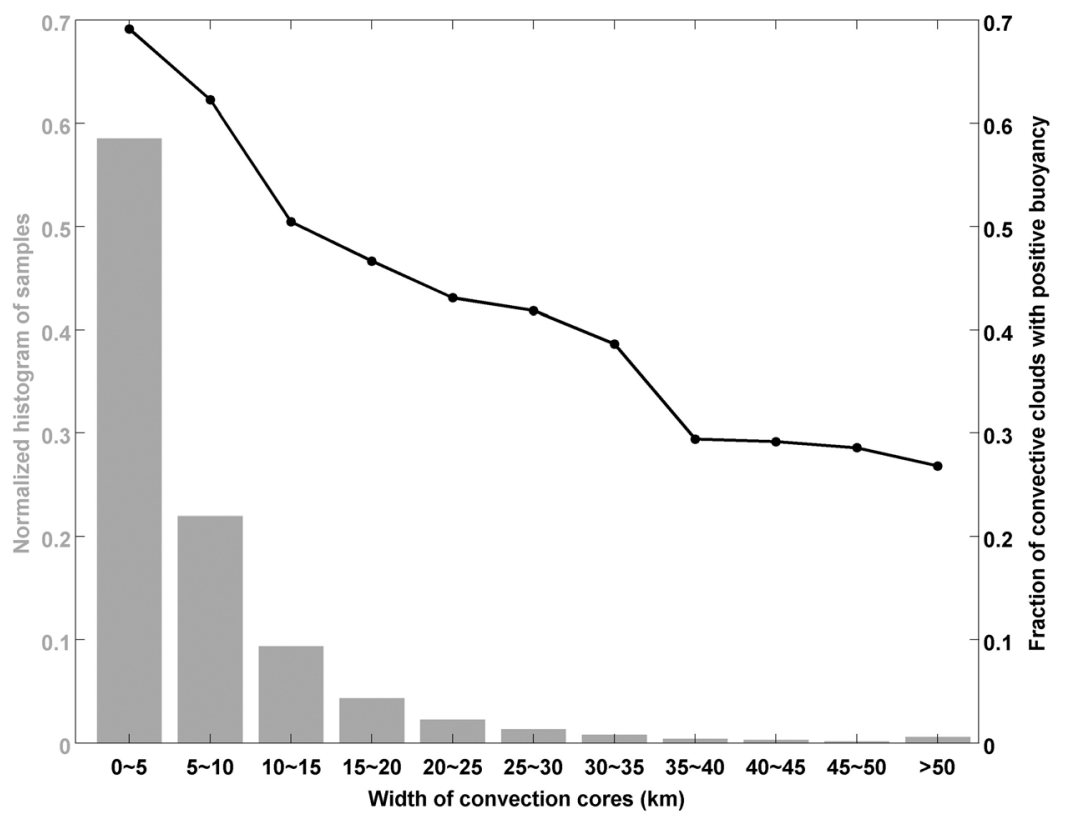

Figure 8. The black line shows the fraction of convective clouds with positive buoyancy sorted by horizontal span of the core of the convective cloud as observed by CloudSat. The gray bars are the normalized number of observations falling into each bin of the horizontal span. Normalization is with respect to the total number of observations.

pronounced for cloud observations. Here, we describe a parallax correction method for collocating CloudSat and MODIS data for the study of tropical convective clouds. The impact of the parallax correction on the statistics of convective cloud properties, such as cloud top temperature (CTT) and buoyancy, is examined. Comparisons are also made with previous studies of tropical convection using the same data sets that avoided the parallax problem by imposing a flat-top condition on selection of convective clouds. Although effectively avoiding the parallax problem, the flat-top condition biases the statistics toward convection at mature or dissipating stages when convective plumes tend to flatten out to form cirrus anvils. Analysis of a whole year (2008) of data is conducted over the tropical region $\left(30^{\circ} \mathrm{S}-30^{\circ} \mathrm{N}\right)$. The main findings are summarized as follows:

[24] 1. Parallax correction reduces the CTT of convective clouds; the magnitude of the reduction increases with cloud top height $(\mathrm{CTH})$. This is because without parallax correction, the satellite views the surrounding area of a convective plume which is likely to be warmer than the plume (to visualize this, just imagine that a convective plume usually bulges up from the nearby clouds). This effect is more pronounced for higher $\mathrm{CTH}$ because a taller convective plume is less likely to be sandwiched by still taller (and colder) neighbors.

[25] 2. Parallax correction reduces the spread or standard deviation of CTT. This can be understood as reflecting an overall improved collocation of CTH (from CloudSat) and $T_{B}$ (from MODIS). In other words, the estimated $T_{B}$ is now more closely clustered around the true value for that height level (e.g., without parallax correction, we see a CTT of $272.3 \mathrm{~K}$ that belongs to a convective cloud with $\mathrm{CTH}$ of $15.18 \mathrm{~km}$, as shown in Figure 2). The decrease in spread is more pronounced for taller convection than for lower ones for the same reason that the parallax correction on CTT increases with $\mathrm{CTH}$. Together, these changes suggest that parallax correction is particularly important for studying deep convection.

[26] 3. As a natural consequence of the decrease in CTT, the fraction of convection with positive buoyancy decreases after parallax correction. Again, the effect is greater for deep convection (with CTH $>10-12 \mathrm{~km}$ ). Comparisons with previous studies, which had no parallax correction but imposed a flat-top condition, show that indeed the fraction of positive buoyancy is smaller when only mature and dissipating convection is selected.

[27] With parallax correction applied, we further explored the diurnal and ocean-to-land contrasts in convective cloud buoyancy. Results are consistent with our general understanding of tropical convection, namely, diurnal difference is larger over land than over ocean and afternoon convection is more rigorously growing than the counterpart after midnight. Finally, the dependence of the fraction of positive buoyancy on cloud size is analyzed. Smaller convection is found to be more likely to have positive buoyancy, which is consistent with our understanding of convective life cycle.

[28] This study is part of an ongoing activity that seeks to understand the underlying convective processes through synergistic measurements from the A-Train constellation. In a broader sense, this paper underscores the subtlety of matching satellite observations from different platforms, even when these satellites fly in close formation like the A-Train constellation. Hopefully, this study can be helpful for refining algorithms used to collocate A-Train data products for the study of clouds (and probably aerosols as well). It would also be useful for any future efforts on coordinating cloud observations from different satellite platforms. 
[29] Acknowledgments. We wish to thank W.-K. Tao and X. Zeng at NASA GSFC for helpful discussions and feedback. We also thank two reviewers for their useful comments and suggestions. The CloudSat data were obtained from the CloudSat Data Processing Center. The MODIS data were obtained from NASA Goddard DISC. The ECMWF interim data used in this study were obtained from http://data.ecmwf.int/data/. This research is supported by the NASA MAP project under grant NNX09AJ46G awarded to the University of Michigan and the NASA CloudSat/CALIPSO Science Team under grant NNX10AM31G awarded to the City University of New York (CUNY).

\section{References}

Barnes, W. L., T. S. Pagano, and V. V. Salomonson (1998), Prelaunch characteristics of the Moderate Resolution Imaging Spectroradiometer (MODIS) on EOS-AM1, IEEE Trans. Geosci. Remote Sens., 36, 1088-1100, doi:10.1109/36.700993.

Diner, D. J., et al. (1998), Multi-angle imaging spectroradiometer (MISR) instrument description and experiment overview, IEEE Trans. Geosci. Remote Sens., 36, 1072-1087, doi:10.1109/36.700992.

Ellingson, R. G., J. Ellis, and S. Fels (1991), The intercomparison of radiation codes used in climate models: Longwave results, J. Geophys. Res., 96, 8929-8953, doi:10.1029/90JD01450.

Hasler, A. F. (1981), Stereographic observations from geosynchronous satellites: An important new tool for the atmospheric sciences, Bull. Am. Meteorol. Soc., 62, 194-212, doi:10.1175/1520-0477(1981)062<0194 SOFGSA $>2.0 . \mathrm{CO} ; 2$.

Hong, G., P. Yang, A. K. Heidinger, M. J. Pavolonis, B. A. Baum, and S. E. Platnick (2010), Detecting opaque and nonopaque tropical upper tropospheric ice clouds: A trispectral technique based on the MODIS 8-12 $\mu \mathrm{m}$ window bands, J. Geophys. Res., 115, D20214, doi:10.1029/ 2010JD014004.

Kahn, B. H., et al. (2008), Cloud type comparisons of AIRS, CloudSat, and CALIPSO cloud height and amount, Atmos. Chem. Phys., 8, 1231-1248, doi:10.5194/acp-8-1231-2008

Kato, S., S. Sun-Mack, W. F. Miller, F. G. Rose, Y. Chen, P. Minnis, and B. A. Wielicki (2010), Relationships among cloud occurrence frequency, overlap, and effective thickness derived from CALIPSO and CloudSat merged cloud vertical profiles, J. Geophys. Res., 115, D00H28, doi:10.1029/2009JD012277.

Liu, C., E. Zipser, G. Mace, and S. Benson (2008), Implications of the differences between daytime and nighttime CloudSat observations over the tropics, J. Geophys. Res., 113, D00A04, doi:10.1029/2008JD009783.

Luo, Z., G. Y. Liu, and G. L. Stephens (2008), CloudSat adding new insight into tropical penetrating convection, Geophys. Res. Lett., 35, L19819, doi:10.1029/2008GL035330.
Luo, Z., G. Y. Liu, G. L. Stephens, and R. H. Johnson (2009), Terminal versus transient cumulus congestus: A CloudSat perspective, Geophys. Res. Lett., 36, L05808, doi:10.1029/2008GL036927.

Luo, Z. J., G. Y. Liu, and G. L. Stephens (2010), Use of A-Train data to estimate convective buoyancy and entrainment rate, Geophys. Res. Lett., 37, L09804, doi:10.1029/2010GL042904.

Nishihama, M., R. Wolfe, D. Solomon, F. Patt, J. Blanchette, A. Fleig, and E. Masuoka (1997), MODIS level 1A Earth location: Algorithm theoretical basis document version 3.0, report, MODIS Sci. Data Support Team, NASA Goddard Space Flight Cent., Greenbelt, Md.

Parkinson, C. L. (2003), Aqua: An Earth-observing satellite mission to examine water and other climate variables, IEEE Trans. Geosci. Remote Sens., 41, 173-183, doi:10.1109/TGRS.2002.808319.

Platnick, S., et al. (2003), The MODIS cloud products: Algorithms and examples from Terra, IEEE Trans. Geosci. Remote Sens., 41, 459-473, doi:10.1109/TGRS.2002.808301.

Simmons, A., S. Uppala, S. Dee, and S. Kobayashi (2006), ERA-interim: New ECMWF reanalysis products from 1989 onwards, ECMWF Newsl., $110,25-35$.

Stephens, G. L., et al. (2002), The CloudSat mission and the A-Train: A new dimension of space-based observations of clouds and precipitation, Bull. Am. Meteorol. Soc., 83, 1771-1790, doi:10.1175/BAMS-8312-1771.

Stephens, G. L., et al. (2008), CloudSat mission: Performance and early science after the first year of operation, J. Geophys. Res., 113, D00A18, doi:10.1029/2008JD009982.

Tian, B., B. J. Soden, and X. Wu (2004), Diurnal cycle of convection, clouds, and water vapor in the tropical upper troposphere: Satellites versus a general circulation model, J. Geophys. Res., 109, D10101, doi:10.1029/ $2003 J D 004117$.

Uppala, S., S. Dee, S. Kobayashi, P. Berrisford, and A. Simmons (2008), Toward a climate data assimilation system: Status update of ERAinterim, ECMWF Newsl., 115, 12-18.

Yang, G.-Y., and J. M. Slingo (2001), The diurnal cycle in the tropics, Mon. Weather Rev., 129, 784-801, doi:10.1175/1520-0493(2001)129<0784: TDCITT $>2.0 . \mathrm{CO} ; 2$.

X. Huang and C. Wang, Department of Atmospheric, Oceanic and Space Sciences, University of Michigan, 2455 Hayward St., Ann Arbor, MI 48109-2143, USA. (xianglei@umich.edu)

Z. J. Luo, Department of Earth and Atmospheric Sciences, City College of New York, New York, NY 10031, USA. 